Bioinspired, Biomimetic and Nanobiomaterials Volume 4 Issue BBN1

Direct bioelectrocatalysis at the interfaces by genetically engineered dehydrogenase

Yucesoy et al.
Pages 79-89 http://dx.doi.org/10.1680/bbn. 14.00022 Memorial Issue Research Paper

Received 27/05/2014_Accepted 09/12/2014 Published online 13/12/2014

Keywords: biointerfaces/biomimetic devices/biosensors

\title{
Direct bioelectrocatalysis at the interfaces by genetically engineered dehydrogenase
}

1 Deniz Tanil Yucesoy MSC

PhD Student, Materials Science and Engineering, University of Washington, Seattle, WA, USA

2 Banu Taktak Karaca MSC

Visiting PhD Student, Bioengineering Research Center, University of Kansas, Lawrence, KS, USA

PhD Student, Molecular Biology and Genetics, Istanbul Technical University, Istanbul, Turkey

3 Sibel Cetinel PhD

Postdoctoral Researcher, Molecular Biology and Genetics, Istanbul Technical University, Istanbul, Turkey

4 Huseyin Burak Caliskan

MSc Student, Molecular Biology and Genetics, Istanbul Technical University, Istanbul, Turkey
5 Esref Adali PhD

Professor, Faculty of Computer and Informatics, Istanbul Technical University, Istanbul, Turkey

6 Nevin Gul-Karaguler PhD

Professor, Molecular Biology and Genetics, Istanbul Technical University, Istanbul, Turkey

7 Candan Tamerler PhD*

Professor, Department of Mechanical Engineering, University of Kansas, Lawrence, KS, USA

Bioengineering Research Center, University of Kansas, Lawrence, KS, USA

There is an emerging interest in developing bio-functionalisation routes serving as platforms for assembling diverse enzymes onto material surfaces. Specifically, the fabrication of next-generation, laboratory-on-a-chip-based sensing and energy-harvesting systems requires controlled orientation and organisation of the proteins at the inorganic interfaces. Herein, the authors take the initial steps towards designing multifunctional, enzyme-based platforms by genetically integrating the engineered materialselective peptide tags for tethering redox enzymes onto electrode surfaces. The authors engineered a fusion protein that genetically conjugates gold-binding peptide to formate dehydrogenase derived from Candida methylica. The expressed proteins were tested for both enzyme activity and self-directed gold-surface functionalisation ability. Their findings demonstrate the successful self-immobilisation of the engineered enzyme onto different gold electrodes while retaining the catalytic activity. Building on the functionalisation by the peptides, a fusion enzyme-integrated circuit-based biosensor system was designed. The catalytic conversion of the formate by the engineered dehydrogenase was successfully monitored on the electrode surface at subsequent intervals. The engineered peptide-mediated self-integrated electrode systems can be extended to develop a wide range of biosensing and energy-harvesting platforms using different combinations of materials and biomolecules. This paper contains supporting information that will be made available online once the issue is published. In the meantime, if you wish to get a copy of the supplementary file, please contact the Journals Editor, Sarah Brown, at sarah.brown@icepublishing.com.

\section{Introduction}

The functional integration of biomolecules onto solid material interfaces is attracting interests more than ever due to their impact on a diverse array of application areas. ${ }^{1-5}$ The recent advances in translating the biomolecular mechanisms into the hybrid materials and system designs promise novel methodologies that may transform some of the authors' engineering approaches. ${ }^{6-13}$ One of the major challenges in such systems is to have control at the bio-nanomaterial interface. The biomolecules need to be integrated at the material interfaces without compromising their spatial distribution, organisation and orientation-dependent activity within a desired proximity. ${ }^{3,4,7,12}$ Among nature's indispensable repertoire, enzymes, due to their exquisite catalytic features, are certainly one of the most appealing candidates to be utilised as an internal component in next-generation devices. ${ }^{9}{ }^{12,14}$ However, their spatial distribution with the desired orientation on the solid surfaces, operational stability and long-term reuse are among the critical parameters that limit their wide-range integration to functional materials. ${ }^{2,10-15}$ There is an urge to develop biological surface functionalisation approaches that will give the ability to control the desired functions at the bio-nanomaterial interfaces with tunability over a multitude of scales.

Physical adsorption is one of the simplest ways to immobilise enzyme molecules onto support surfaces. However, controlling the interactions between the adsorbed molecule and the surface is 
Bioinspired, Biomimetic and Nanobiomaterials Volume 4 Issue BBN1
Direct bioelectrocatalysis at the interfaces by genetically engineered dehydrogenase Yucesoy et al. difficult due to the weak and the non-specific nature of the attachment process. ${ }^{16-18}$ Chemical coupling that provides a more stable interfacial interaction is a widely used immobilisation strategy. ${ }^{19-21}$ Self-assembled monolayers (SAMs) have been the indispensable approach to functionalise the metallic surfaces for attaching any type of biomolecules. Here, the covalent linkage between a surface and molecule is formed by the monolayers of alkane chains that contain different functional groups, dependent on the surface chemistry of the support material and the biomolecule. ${ }^{22-24}$ Specifically, the utilisation of the monolayers of alkane-thiolates, that contain carboxylic acid or amine terminal groups, is well documented for gold surfaces..$^{22}$ Despite the enhanced stability of the coupling interaction, a major drawback of this approach is the low retention of enzyme activity due to the randomly introduced covalent linkages during the coupling reaction. Once formed, those covalent linkers establish very rigid attachments and prevent the immobilised biomolecules from positioning themselves towards their substrates and/or cofactors. ${ }^{19,22,25}$ Due to the structurally anisotropic nature of the enzyme molecules, the lack of orientation control prevents the utilisation of the enzyme's full potential, especially for bioelectric and biofuel-cell devices. ${ }^{26}$ Furthermore, single-layered supports, such as graphene, are highly sensitive to the SAM-based surface activation methods, which may dramatically disrupt its unique electronic properties. ${ }^{27,28}$ The realisation of nextgeneration hybrid devices integrated with biomolecules requires the development of more efficient immobilisation methods. These techniques should provide a better communication between the biological molecules and their solid surfaces built on controllable interactions starting at the interfaces.

Over the last decade, combinatorial biology-based selection methods for solid-binding peptides have gained attention as a novel alternative to the conventional surface functionalisation and deposition techniques, due to their ability to bring specific biomolecular recognition and binding properties onto inorganic surfaces. ${ }^{1-4,29-31}$ Moreover, the ease with which these short sequences are genetically incorporated into any permissive site or the C-or N-terminus of an enzyme makes them an attractive option in designing novel biomolecular systems that feature desired multifunctional properties. ${ }^{3,5,15,32}$ This opportunity presents many novel aspects to alter while designing the next-generation molecular systems through biological self-assembly. So far, the authors, and other groups, have designed and verified the abilities of various peptides and proposed many techniques to better understand the related molecular mechanisms leading to controlled interactions at the interfaces. ${ }^{29-36}$ Also, several research groups, including the authors, have demonstrated the use of a variety of solid-binding peptides as anchoring molecules onto the surfaces as well as providing functional integration between the enzymes/ proteins and specific inorganic supports. ${ }^{32-40}$ The biological nature of these short peptide sequences and their vast ability to create selforganised assemblies on a surface under physiological conditions make them highly desirable when compared with their counterparts that may require higher temperatures and $\mathrm{pH}$ values, or other harsh reaction conditions.

Among the industrially important enzymes, oxidoreductases are capable of catalysing key metabolic reactions. These metabolic processes are classified as redox reactions that involve oxidation or reduction of substrate molecules along with a concomitant transfer of electron pairs between the organic substrates and the specific cofactor molecules. ${ }^{41,42}$ Dehydrogenases produce pure chiral molecules with their enantioselective oxidative and reductive catalytic properties. These properties promote these enzymes as highly valuable tools in the pharmaceutical, chemical, agriculture and food processing industries. Nicotinamide adenine dinucleotide $\left(\mathrm{NAD}^{+}\right)$-dependent formate dehydrogenase (FDH, EC 1.2.1.2) is an important member in the oxidoreductase family. After the breakdown of formate by $\mathrm{NAD}^{+}$-dependent dehydrogenases at a close proximity of gold electrode, the electrochemical reduction of $\mathrm{NAD}^{+}$to NADH takes place. The difference in redox potentials between the gold electrode and NADH will lead to further electrochemical oxidation, and as a result two electrons are transferred to the circuit. Due to its ability to regenerate a NADH cofactor by way of an irreversible reaction using a considerably cheaper substrate, FDH is employed in $\mathrm{NAD}^{+} / \mathrm{NADH}$ regeneration processes. $^{43}$ Furthermore, FDHs have been used for sensing applications to detect formate quantitatively as an important fermentation product of aerobic and anaerobic bacteria. ${ }^{44,45}$ The capability to transfer electron pairs between specific substrates and $\mathrm{NAD}^{+}$molecules offers another interesting potential for FDHs as power bioelectronic devices. ${ }^{46}$ The industrial importance of $\mathrm{NAD}^{+}$-dependent FDH has led researchers to develop different kinds of immobilisation strategies through a variety of support materials to efficiently enable the desired use of the enzyme. ${ }^{47-49}$ FDHs have been successfully isolated and produced from many different species, but methanol-consuming yeast species, such as Candida methylica $(\mathrm{cm})$, have received the most attention due to the enhanced stability and relatively high activity of their isolated $\mathrm{NAD}^{+}$-dependent FDHs. ${ }^{45,50,51}$

In this study, the authors genetically engineered $\mathrm{NAD}^{+}$-dependent FDH from $C$. methylica to couple with gold-binding peptide as a novel enzyme with chimeric properties. The resulting fusion enzyme was demonstrated to retain the catalytic activity both in solution- and surface-immobilised forms while gaining additional self-organisation ability verified on a variety of gold electrode surfaces.

\section{Materials and methods}

\subsection{Materials}

The pDrive and pQE2 (Qiagen, Valencia, CA, USA) vectors were used as cloning and expression vectors, respectively, and Escherichia coli strain DH5 $\alpha$-T1 (Invitrogen, Carlsbad, CA, USA) was selected as a host organism. Ampicillin and bacterial media supplements were obtained from Sigma-Aldrich. Nitrilotriacetic 
acid (Ni-NTA) (Qiagen, Valencia, CA, USA) and Glutathione Sepharose (GE Healthcare, Milwaukee, WI, USA) affinity matrices were used for protein purification. Chemicals that were used in buffer preparations were purchased from Sigma-Aldrich. $\mathrm{NAD}^{+}$(Roche, Indianapolis, IN, USA) and sodium formate were used for enzyme activity measurements. The binding studies were done using surface plasmon resonance (SPR) spectroscopy on gold-coated glass slides (Reichert Technologies, Depew, NY, USA).

\subsection{Cloning of the $\mathrm{cmFDH}$ and cmFDH-AuBP2 fusion enzymes}

The $c m \mathrm{FDH}$ gene was obtained in the $\mathrm{pQE} 2$ vector and used as a template for cloning both the $\mathrm{cmFDH}$ and the $\mathrm{cm}$ FDH-AuBP2 fusion proteins. ${ }^{51}$ The $c m \mathrm{FDH}-$ and $c m \mathrm{FDH}-\mathrm{AuBP} 2$-encoding deoxyribonucleic acid (DNA) sequences were constructed using polymerase chain reaction (PCR) by primers specifically designed to add PstI and SacI restriction sites to the N- and C-terminus of the protein-coding region, respectively. The AuBP2 (CGPWALRRSIRRQSYGPC) peptide-coding region was inserted to the N-terminus of the protein by using a double-step PCR using two different primer sequences (see supplementary information for primer sequences). The resulting PCR-amplified protein-coding sequences were first sub-cloned into the pDrive cloning vector and then transferred into the $\mathrm{pQE} 2$ expression vector. They were ligated using a rapid Roche DNA ligation kit. Finally, PreScission Protease recognition site was inserted between the poly-histidine (His) tag and the protein-coding region using specifically designed primers (see supplementary information for primer sequences) in combination with the Gene-Tailor Site-Directed Mutagenesis Kit (Invitrogen, Carlsbad, CA, USA). This modification allowed achieving the removal of poly-His tag by way of PreScission Protease. The resulting constructs were transformed into the expression host $E$. coli $\mathrm{DH} 5 \alpha$-T1 cells by way of chemical transformation.

\subsection{Expression of $\mathrm{cmFDH}$ and the cmFDH-AuBP2 enzymes}

The pQE2-cmFDH or pQE2-cmFDH-AuBP2 plasmid-harbouring cells were used for protein expression studies. First, the cells were grown overnight at $37^{\circ} \mathrm{C}$ in $5 \mathrm{ml}$ of Luria Bertani (LB) media, containing $100 \mu \mathrm{g} / \mathrm{ml}$ ampicillin. Next, $1 \mathrm{ml}$ of the overnight culture was inoculated into the fresh LB media and incubated at $37^{\circ} \mathrm{C}$ until it reached an optical density $\left(\mathrm{OD}_{600}\right)$ of 0.5 . The protein expression was induced with isopropyl $\beta$-D-1-thiogalactopyranoside (IPTG) addition to a final concentration of $0.5 \mathrm{mM}$, and the culture was incubated for $16 \mathrm{~h}$ at $16^{\circ} \mathrm{C}$ with constant agitation (200 rpm). The cells were then harvested following the QIA expression manual (Qiagen, Valencia, CA, USA) and re-suspended in sodium phosphate buffer $\left(50 \mathrm{mM} \mathrm{NaH} \mathrm{PO}_{4}, 300 \mathrm{mM} \mathrm{NaCl}, 20 \mathrm{mM}\right.$ imidazole at $\mathrm{pH}$ 8.0 ) containing $0.5 \mathrm{mM}$ phenylmethanesulfonyl fluoride (PMSF). The cells were lysed by $1 \mathrm{mg} / \mathrm{ml}$ lysozyme treatment for $30 \mathrm{~min}$ on ice and sonicated at $200 \mathrm{~W}$ three times for 10 s. Finally, the resulting cell lysate was centrifuged and the supernatant solution was reserved for further purification.

\subsection{Purification of $\mathrm{cmFDH}$ and cmFDH-AuBP2 enzymes}

The similar affinity purification method, that is, Ni-NTA metalaffinity chromatography, was used to purify the $\mathrm{cm}$ FDH and cmFDH-AuBP2 enzymes. A pre-packed Ni-NTA column was first equilibrated with the sodium phosphate buffer $(50 \mathrm{mM}$ $\mathrm{NaH}_{2} \mathrm{PO}_{4}, 300 \mathrm{mM} \mathrm{NaCl}, 20 \mathrm{mM}$ imidazole at $\mathrm{pH} 8.0$ ), and then the total protein-containing supernatant solution was loaded into the column. The non-specifically bound proteins were removed by applying five column volumes of sodium phosphate buffer (50 $\mathrm{mM} \mathrm{NaH}_{2} \mathrm{PO}_{4}, 300 \mathrm{mM} \mathrm{NaCl}, 50 \mathrm{mM}$ imidazole at $\mathrm{pH} 8.0$ ) containing $1 \%$ Triton $\mathrm{X}-100$ solution. The proteins of interest were eluted by increasing the imidazole concentration in the sodium phosphate buffer up to $250 \mathrm{mM}$. Finally, the purification process was confirmed by the sodium dodecyl sulfate polyacrylamide gel electrophoresis (SDS-PAGE) analysis.

\subsection{Affinity tag (His-tag) removal from enzymes using engineered cleavage site}

The enzymes purified in the sodium phosphate buffer were first exchanged into $1 \mathrm{X}$ PreScission Protease cleavage buffer $(50 \mathrm{mM}$ Tris- $\mathrm{HCl}, 150 \mathrm{mM} \mathrm{NaCl}, 1 \mathrm{mM}$ EDT, $1 \mathrm{mM}$ DTT at $\mathrm{pH}$ 7.0) using a 30000 molecular weight cut-off ultra-filtration centrifugal device (Amicon, Beverly, MA, USA). The His-tag cleavage reaction was then performed using a previously described protocol. ${ }^{33}$ Both the tag-free $c m$ FDH and $c m$ FDH-AuBP2 enzymes were obtained in $20 \mathrm{mM}$ Tris- $\mathrm{HCl}$ buffer at $\mathrm{pH} 8.0$ followed by the purification of respective protein solutions by way of Ni-NTA and Glutathione Sepharose resins under similar conditions that were described in Section 2.4.

\subsection{Enzyme activity measurements}

The steady-state enzyme activity measurements were carried out at $25^{\circ} \mathrm{C}$ in a reaction mixture containing $20 \mathrm{mM}$ Tris- $\mathrm{HCl}$ buffer at $\mathrm{pH} 8.0,1 \mathrm{mM} \mathrm{NAD}{ }^{+}, 0-40 \mathrm{mM}$ formate and $0.4 \mu \mathrm{M}$ enzyme in a total reaction volume of $1 \mathrm{ml}$. The increase in absorption at $340 \mathrm{~nm}$, corresponding to the reduction of $\mathrm{NAD}^{+}$, was monitored and the data were analysed using an enzyme kinetics tool, GRAFIT software (Version 5.0.13, Erithacus Software Ltd, Horley, Surrey, UK). The data were reproduced three times and all the assays were performed in triplicates. The enzyme concentration was determined by Bradford assay using bovine serum albumin standards, at a wavelength of $595 \mathrm{~nm}$.

\subsection{Surface-binding kinetics analysis}

The binding kinetics of $\mathrm{cmFDH}$ and $\mathrm{cm} \mathrm{FDH}-\mathrm{AuBP} 2$ enzymes were performed using a single-channel SPR instrument (Kretschmann configuration) developed by the Reichert Instruments. The buffer 
Bioinspired, Biomimetic and Nanobiomaterials Volume 4 Issue BBN1
Direct bioelectrocatalysis at the interfaces by genetically engineered dehydrogenase Yucesoy et al. solutions were degassed to avoid bubble formation in the flow cell. After establishing a stable baseline signal by flowing $20 \mathrm{mM}$ Tris$\mathrm{HCl}$ buffer, $\mathrm{pH} 8.0$ over the surface, the $\mathrm{cmFDH}$ or $\mathrm{cm}$ FDH-AuBP2 enzyme solutions in given concentrations were flowed through the surface, and their adsorption was monitored. The temperature within the flow cell of the SPR was kept constant at $25^{\circ} \mathrm{C}$ by way of a heating element and a cooling fan controlled by a temperature sensor. All of the solutions used were introduced to the flow cell at a rate of $100 \mu \mathrm{l} / \mathrm{min}$. In the data analysis, the Langmuir isotherm model was used to calculate the association $\left(k_{\mathrm{a}}\right)$, dissociation $\left(k_{\mathrm{b}}\right)^{3}$ and equilibrium $\left(k_{\mathrm{eq}}\right)$ constants of the adsorption process at different enzyme concentrations. ${ }^{52}$

\subsection{Enzyme-activated electrode experiments}

To create an enzyme-activated electrode system, the authors first obtained 525- $\mu \mathrm{m}$ thick silicon wafers coated with a $100-\mathrm{nm}$ gold layer. Titanium of a thickness of $5 \mathrm{~nm}$ was used as an adhesion layer between the gold coating and silicon wafer (Platypus Technologies, Madison, WI, USA). The gold-coated substrates were cut in $1 \mathrm{~cm}$ $\times 1 \mathrm{~cm}$ dimensions to use as gold electrodes. The molecules of cmFDH-AuBP2 enzyme were next adsorbed onto one of the electrodes to activate the gold surface. For the adsorption process, $200 \mu \mathrm{l}$ of $10 \mu \mathrm{M} c m$ FDH-AuBP2 enzyme in $20 \mathrm{mM}$ Tris- $\mathrm{HCl}$ buffer, $\mathrm{pH} 8 \cdot 0$, was applied onto a gold surface and incubated for $15 \mathrm{~min}$ in a humidity chamber at room temperature. The enzymeimmobilised electrode was subsequently washed with Milli-Q water to get rid of excess proteins from surface before placing into a sterile beaker in parallel with the bare gold electrode. This set-up acted as an electrochemical cell after the beaker was filled with $20 \mathrm{mM}$ Tris- $\mathrm{HCl}, \mathrm{pH} 8 \cdot 0$, and $0 \cdot 1 \mathrm{M} \mathrm{KCl}$ until both electrodes were submerged. A $22-\mathrm{K} \Omega$ resistor was attached to the lead of the electrodes. The output voltage of the cell was measured by an HP 974A multimeter.

\section{Results and discussion}

The authors genetically engineered a novel fusion enzyme, $c m$ FDH, which demonstrates the self-organisation ability on a gold surface while retaining its inherent catalytic activity. The efficiency of the solid-binding peptide-enabled anchoring of $c m$ FDH onto gold surfaces was investigated with respect to its solid-binding ability as well as the overall enzyme activity by comparing the kinetic activity parameters of the $c m$ FDH-AuBP2 engineered enzyme to the control $\mathrm{cm} F \mathrm{FH}$. Furthermore, the authors demonstrated the oxidation of formate in the enzymeactivated electrode system. Their approach built on the three steps is summarised in Figure 1.

\subsection{Genetically engineered FDH with the gold surface recognition}

A biocombinatorially selected and characterised gold-binding peptide $^{53}$ (AuBP2) was used as a fusion partner to $\mathrm{cmFDH}$. The
AuBP2 peptide sequence was inserted between the poly-His tag and the $\mathrm{N}$-terminus of the $\mathrm{cm} \mathrm{FDH}$-coding region using a GGGS (Glycine-Glycine-Glycine-Serine) spacer to allow the efficient peptide display (Figure 2). The resulting engineered protein thereby ensures that the gold-binding peptide region is freely exposed to the environment without any restriction on its conformation as well as any potential interference with the enzyme.

To purify the expressed recombinant protein in high yields, the authors employed a poly-His affinity tag-based approach. It has been previously shown that the N-terminal His tag does not influence the activity of $\mathrm{cmFDH} .{ }^{45,51}$ On the other hand, multi-histidine residues have a non-specific, yet considerable, high affinity to a variety of metal surfaces including gold. To avoid the unpredictable properties of poly-His affinity tag on newly introduced specific gold surface recognition ability, both the peptide-fused and control constructs were specifically designed by introducing a protease cleavage site at the end of poly-His tag region. This extra design step in their cloning approach allowed for the complete removal of the poly-His tag region from the protein. The PreScission Protease recognition and cleavage sites were introduced to the final enzyme constructs using a site-directed mutagenesis strategy. The schematic representation of AuBP2-incorporated $\mathrm{cmFDH}$, spatial organisation of poly-His tag, cleavage site and gold-binding peptide regions are depicted in Figure 3(a). The plasmids encoding $c m \mathrm{FDH}$ and $\mathrm{cm} \mathrm{FDH}-\mathrm{AuBP} 2$ proteins were successfully expressed in E. coli $\mathrm{DH} 5 \alpha-\mathrm{T} 1$ strains and purified using Ni-NTA matrices under native conditions. The purity and molecular weights of the expressed proteins were analysed by SDS-PAGE (Figure 3(b)). The protein bands indicating $\mathrm{cm} F \mathrm{FH}$ and $\mathrm{cm} F \mathrm{FH}-\mathrm{AuBP} 2$ were observed to be approximately 41 and $43.5 \mathrm{kDa}$, respectively, referring to the expected molecular weights for both enzymes following the inclusion of new sequences.

\subsection{Enzymatic activities of the fusion enzyme}

On the successful completion of the expression and purification processes, the catalytic activity of the wild-type and engineered enzymes were analysed (Table 1). The unmodified wild-type $c m$ FDH shows a similar catalytic activity $\left(0.592 \pm 0.019 \mathrm{~s}^{-1}\right)$ values when compared with other studies in the literature $\left(0 \cdot 5 \pm 0 \cdot 1 \mathrm{~s}^{-1}\right)$. This confirms that the inclusion of the new excision site to remove the poly-His tag from the enzyme did not affect the enzymatic activity. ${ }^{51}$

Many of the immobilisation approaches explored so far result in a significant loss of catalytic enzymatic functionality, potentially due to the randomly introduced covalent bonds between the enzyme and the surface. ${ }^{12,15}$ In this case, the authors added a new functionality to the enzyme to attain surface functionalisation ability; they first tested if the enzyme would retain its catalytic activity following the insertion of the new gold-binding domain. The calculated enzyme kinetic parameters 


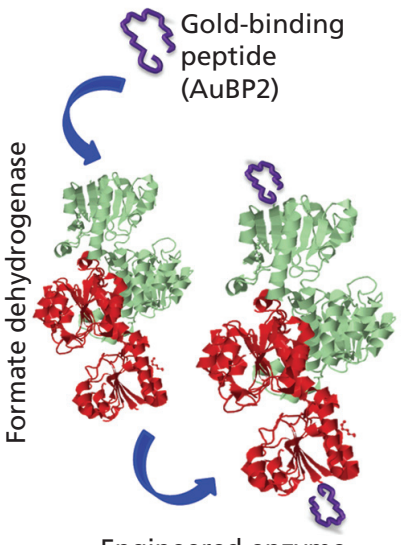

Engineered enzyme

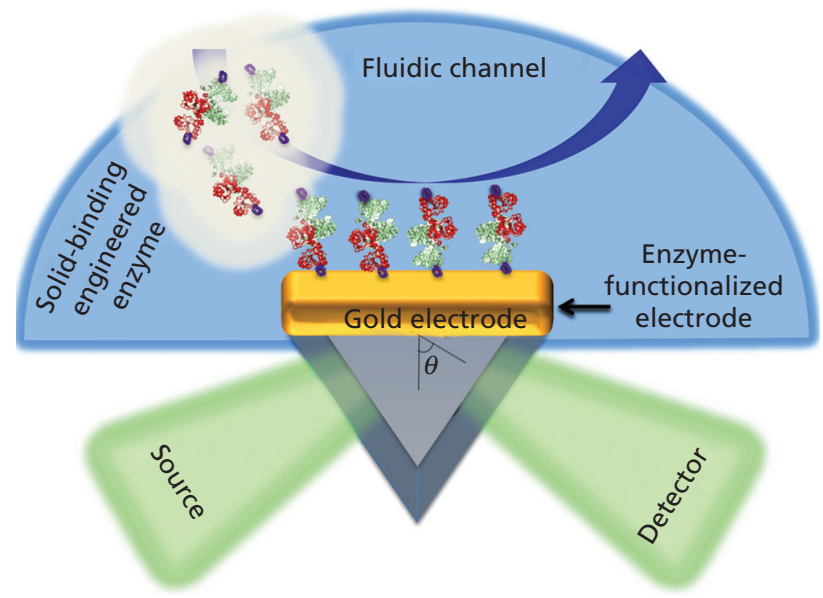

(b)

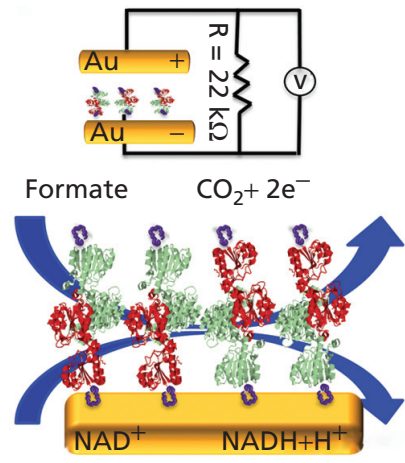

Enzyme-activated electrode

(a)

Figure 1. A schematic illustration of the three-step-based

experimental design approach for genetically engineered enzyme-

based self-organisation leading to a circuit-based sensor

$k_{\text {cat }}$, which indicates the turnover rate of substrate to product, and $K_{\mathrm{m}}$ (the Michaelis constant), which describes an enzyme's affinity to its substrate, are provided in Table 1 . The $k_{\text {cat }}$ value obtained for the $c m$ FDH-AuBP2 $\left(0 \cdot 615 \pm 0.021 \mathrm{~s}^{-1}\right)$ was very close to that of $c m$ FDH $\left(0.592 \pm 0.019 \mathrm{~s}^{-1}\right)$, which suggests that the enzymatic breakdown of formate is similar for both enzymes. Furthermore, there was no significant difference in the substrate affinities $\left(K_{\mathrm{m}}\right)$ of $c m \mathrm{FDH}-\mathrm{AuBP} 2$ and $c m$ FDH. The ratio of $k_{\text {cat }} / K_{\mathrm{m}}$ is an indicator of the overall catalytic efficiency of the enzyme. In their case, there was less than $2 \%$ difference on the overall $k_{\text {cat }} / K_{\mathrm{m}}$ values between the wild-type and fusion enzymes. This difference was negligible enough to confirm that the apparent kinetic parameters of the wild-type $\mathrm{cmFDH}$ were not affected by the genetic fusion of AuBP2 and the enzyme activity was retained.

\subsection{Gold-binding activity of the fusion enzyme}

Here, the authors used the SPR spectroscopy to characterise the binding of the engineered fusion enzyme, that is, $c m \mathrm{FDH}-\mathrm{AuBP} 2$, and the control enzyme, that is, $c m \mathrm{FDH}$, on the gold surface.

Both enzymes were prepared at $0 \cdot 25,0 \cdot 5$ and $1 \mu \mathrm{M}$ concentrations, and their respective SPR sensograms were recorded (see supplementary information for SPR analysis). Then, the apparent binding rates $\left(k_{\mathrm{obs}}\right)$ of both enzymes were derived by non-linear curve fitting to the Langmuir binding isotherm. ${ }^{52}$ The kinetic adsorption and desorption parameters, given in Table 2, were calculated using a linear regression model (least-squares fit), according to Equation 1:

1.

$$
k_{\mathrm{obs}}=k_{\mathrm{a}} C+k_{\mathrm{d}}
$$

where $k_{\mathrm{a}}$ (slope) and $k_{\mathrm{d}}$ (intercept) are the association and dissociation rate constants, respectively, and $C$ is the concentration. ${ }^{52}$ The equilibrium constant, $k_{\mathrm{eq}}$, can then be calculated using the ratio $k_{\mathrm{a}} / k_{\mathrm{d}}{ }^{52}$ The adsorption rate of the control protein $\left(k_{\mathrm{a}}\right.$ of $2.38 \times 10^{-3}$ $\mathrm{M}^{-1} \mathrm{~s}^{-1}$ ), that is, $c m \mathrm{FDH}$, was considerably low for the gold surface, which could be attributed to the non-specific interactions that were possibly caused by the presence of surface-exposed histidine and cysteine residues. Although these outer surface enzyme residues were known to interact with the gold surface, it was difficult to form a stable enzyme layer and thus the enzyme could be easily washed off the surface. However, the effect of AuBP2 on the binding ability of the fusion enzyme was drastic. Compared with the wild-type enzyme, there was approximately a 4.3-fold enhancement in the association rate constant and roughly a threefold decrease in the dissociation rate constant, leading to a 13-fold increase in the equilibrium constant $\left(k_{\mathrm{eq}}\right.$ of 15.564 compared with $1 \cdot 214)$. Figure 4(a) shows the surface affinities of the enzymes at a protein concentration of $1 \mu \mathrm{M}$. At this concentration, the maximum loading capacity of the sensor was estimated as $1.61 \mathrm{ng} / \mathrm{mm}^{2}$. Their adsorption differences indicate that the AuBP2 peptide tag provides an anchor for the fusion enzyme. Likewise, the standard Gibbs free energy $\left(\Delta G_{\text {ads }}\right.$ ) of adsorption (molarity representation) for the both $c m$ FDH and $c m$ FDH-AuBP2 monolayers was calculated using Equation $2^{52}$ :

$$
\text { 2. } \Delta G_{\text {ads }}=-R T \ln \left(k_{\text {eq }} C\right)
$$

where $k_{\text {eq }}$ is the equilibrium constant $\left(k_{\mathrm{a}} / k_{\mathrm{d}}\right), C$ is the biomolecule concentration, $R$ is the molar gas constant and $T$ is the temperature in Kelvin. The $\Delta G_{\text {ads }}$ values for the $\mathrm{cmFDH}$ and $\mathrm{cm}$ FDH-AuBP2 were found to be -0.115 and $-1.624 \mathrm{kcal} / \mathrm{mol}$, respectively. These negative $\Delta G_{\text {ads }}$ values show the spontaneity of the interaction. 
Bioinspired, Biomimetic and Nanobiomaterials Volume 4 Issue BBN1
Direct bioelectrocatalysis at the interfaces by genetically engineered dehydrogenase Yucesoy et al.
The higher change in the $\Delta G_{\text {ads }}$ value for $c m$ FDH-AuBP2 may be contributed to the fast binding process.

\subsection{Engineered enzyme-activated sensor}

The successful design of any enzyme-based device is dependent on the efficiency of the immobilisation strategy and the catalytic activity of the employed enzyme on its associated surface. With

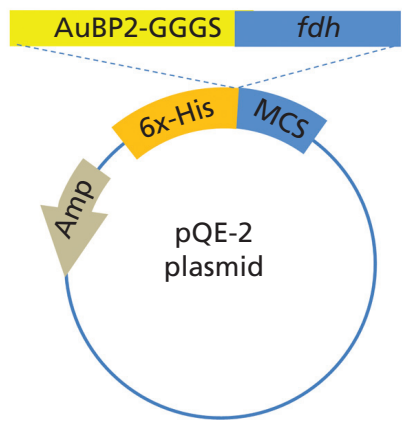

(a)

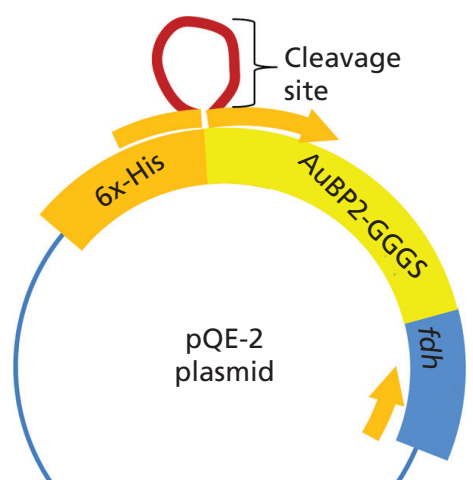

(c)

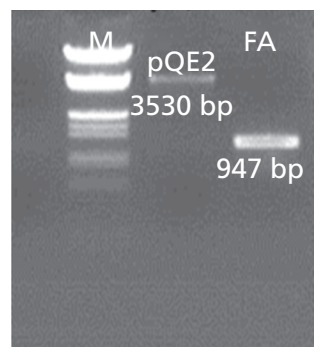

(b)

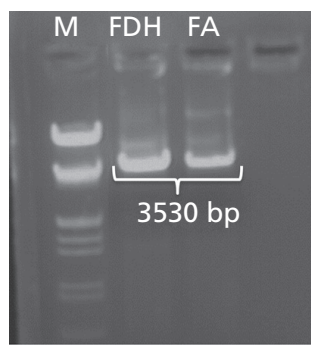

(d)
Figure 2. (a) Vector construction of the $\mathrm{cmFDH}-\mathrm{AuBP} 2$ fusion protein, (b) agarose gel images of Lambda DNA marker (M), Pstl- and Sacldigested pQE2 vector (pQE2) and cmFDH-AuBP2 (FA), (c) a schematic presentation of the protease recognition site introduced to the $\mathrm{cmFDH}-\mathrm{AuBP} 2$ fusion protein, (d) agarose gel images of Lambda DNA marker (M) and PCR products of the pQE2-cmFDH (FDH) and pQE2-cmFDH-AuBP2 (FA) vectors following the site-directed mutagenesis reactions this aim in mind, the fusion enzyme, that is, $c m$ FDH-AuBP2, was immobilised onto a gold electrode surface and tested for its catalytic activity. The authors monitored the conversion of formate to carbon dioxide $\left(\mathrm{CO}_{2}\right)$ electrochemically by designing a circuit-based system consisting of two gold electrodes submerged in solution ( $20 \mathrm{mM}$ Tris- $\mathrm{HCl}$ buffer, $\mathrm{pH} 8 \cdot 0$, and $0 \cdot 1 \mathrm{M} \mathrm{KCl}$ ) and coupling the system with a $22-\mathrm{K} \Omega$ resistor, which was used as a load. Figure 5 illustrates the experimental set-up for monitoring the conversion of formate by the enzyme-activated gold electrode. To activate the selected gold electrode, $10 \mu \mathrm{M}$ of $\mathrm{cmFDH}-\mathrm{AuBP} 2$ was applied on the surface. After allowing enough contact time with the surface, the electrode was washed by the buffer to get rid of excess enzyme that may not be contacting the surface directly but interfering with the protein film. The enzymeactivated electrode was then placed into a sterile beaker vertically, facing the bare gold electrode. The submerged gold electrodes were then connected in parallel to the resistor. The observed potential difference ( $V$, voltage) between the electrodes was read by a digital multimeter placed in parallel with the resistor. After establishing a baseline measurement, $0.25 \mathrm{mM}$ formate as the substrate and $1 \mathrm{mM} \mathrm{NAD}^{+}$as the cofactor were added to the system, and the output voltage was monitored continuously. The energy released in the reaction due to the movement of electrons in the designed circuit gave rise to a potential difference equal to the electromotive force $(\mathrm{emf}, \varepsilon) .^{54-56}$ The resulting change in current across the circuit elements was calculated by using Ohm's law equation (Equation 3):

3.

$$
V=I R
$$

where $V$ is the potential difference measured across the resistor in units of volts $(\mathrm{V}), I$ is the current through the resistance in units of amperes (A) and $R$ is the resistance of the circuit in units of ohms $(\Omega)$.

The initial output voltage was first recorded as $270 \mathrm{mV}$, and then the resistor was connected to the system and the consequent voltage drop was observed (Figure 6). Then, $0.25 \mathrm{mM}$ formate and $1 \mathrm{mM} \mathrm{NAD}^{+}$were added to the solution $(\sim 230 \mathrm{mV})$ to monitor the enzyme-based electrochemical conversion. Herein, the enzyme catalysed the formate oxidation by $\mathrm{NAD}^{+}$until all formate was converted into its products of $\mathrm{CO}_{2}, \mathrm{NADH}$ and $\mathrm{H}^{+}$. There was a rise in the voltage to about $250 \mathrm{mV}$ due to the conduction of electrons through the wire. The consecutive additions of formate resulted in

\begin{tabular}{lccc} 
& cmFDH & cmFDH-AuBP2 & Pure FDH after digestion of His-tag ${ }^{51}$ \\
$V_{\text {max }}:$ abs/min & $0.083 \pm 0.003$ & $0.092 \pm 0.003$ & - \\
$K_{m}: m M$ & $5.219 \pm 0.689$ & $5.549 \pm 0.733$ & $4.49 \pm 0.6$ \\
$K_{\text {cat }}: s^{-1}$ & $0.592 \pm 0.019$ & $0.615 \pm 0.021$ & $0.5 \pm 0.1$ \\
$K_{\text {cat }} / K_{m}$ & $0.113 \pm 0.028$ & $0.111 \pm 0.028$ & 0.1 \\
\hline
\end{tabular}

Table 1. Apparent kinetic parameters (data represent mean \pm SD) 
Bioinspired, Biomimetic and Nanobiomaterials Volume 4 Issue BBN1
Direct bioelectrocatalysis at the interfaces by genetically engineered dehydrogenase Yucesoy et al.

\begin{tabular}{lcc} 
& $c m F D H$ & $c m F D H-A u B P 2$ \\
$k_{\mathrm{a}} \times 10^{3}: \mathrm{M}^{-1} \mathrm{~s}^{-1}$ & 2.38 & 10.35 \\
$k_{\mathrm{d}} \times 10^{3}: \mathrm{s}^{-1}$ & 1.96 & 0.665 \\
$k_{\mathrm{a}} / k_{\mathrm{d}}: \mathrm{M}^{-1}$ & 1.214 & 15.564 \\
$\Delta G_{\mathrm{ads}}: \mathrm{kcal} / \mathrm{mol}$ & -0.115 & -1.624 \\
\hline
\end{tabular}

Table 2. Binding constants of $\mathrm{cmFDH}$ and $\mathrm{cmFDH}-\mathrm{AuBP} 2$ an approximately $10 \%$ increase in the output voltage, which was maintained over a 10-min period. Then, a decrease in the output voltage was observed following the complete conversion of the formate. The system shown here is relatively stable over a range of $\mathrm{pH}(6-9.5)$ and temperature $\left(16-40^{\circ} \mathrm{C}\right)$. The activity was shown to be preserved after five cycles. Overall, the results demonstrate the catalytic capability of the immobilised enzyme using a bioengineered circuit design. The results also indicate the potential

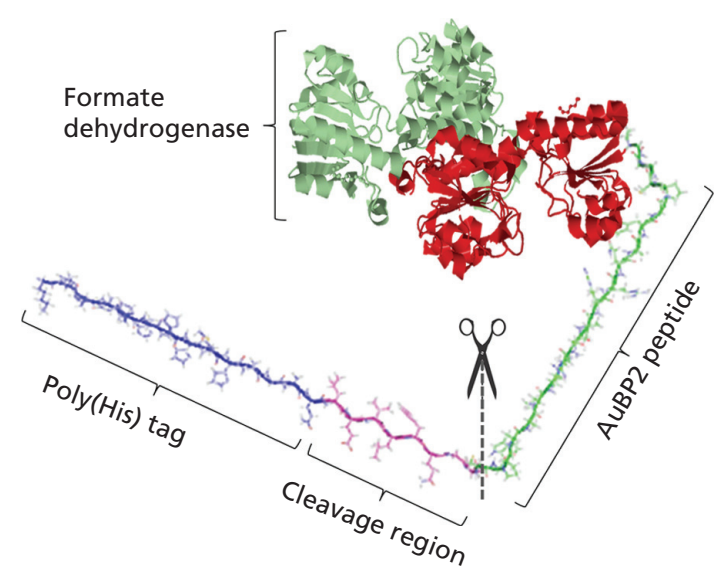

(a)

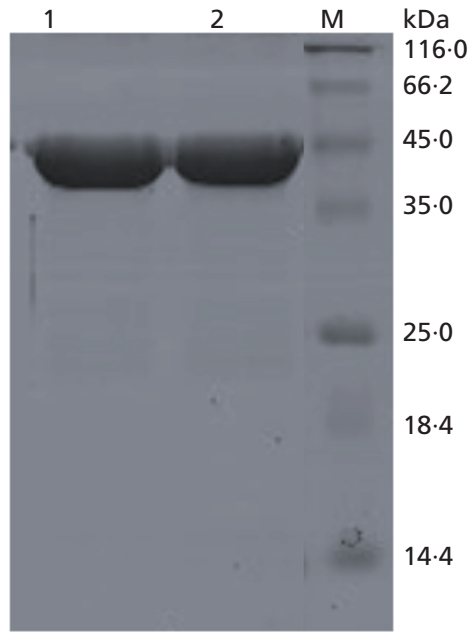

(b)
Figure 3. (a) The cmFDH-AuBP2 fusion protein with poly-His tag and PreScission Protease cleavage sites (the three-dimensional structure of FDH is adapted from PDB ID: $2 J 6 I$ and recoloured.), ${ }^{56}$ (b) SDS-PAGE image of purified enzymes after the removal of poly-His tag; lane 1: $\mathrm{cmFDH}$ and lane 2: $\mathrm{cmFDH}-\mathrm{AuBP2}$, M: protein weight marker with corresponding molecular masses

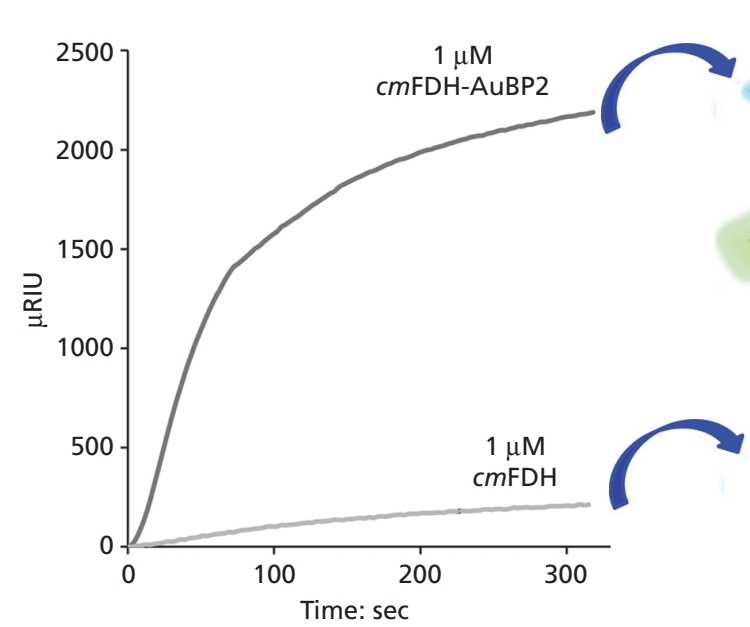

(a)

Figure 4. (a) Adsorption kinetics of constructed gold-binding peptide-fused FDH (cmFDH-AuBP2) and control ( $c m F D H)$ enzymes. A schematic demonstration of the difference in the protein-binding characteristics on gold-coated SPR chips, that is, cmFDH-AuBP2 (b) and $\mathrm{cmFDH}$ (c) (the three-dimensional structure of FDH is adapted from PDB ID: 2J6I and recoloured) ${ }^{56}$ 
Bioinspired, Biomimetic and Nanobiomaterials Volume 4 Issue BBN1
Direct bioelectrocatalysis at the interfaces by genetically engineered dehydrogenase Yucesoy et al.

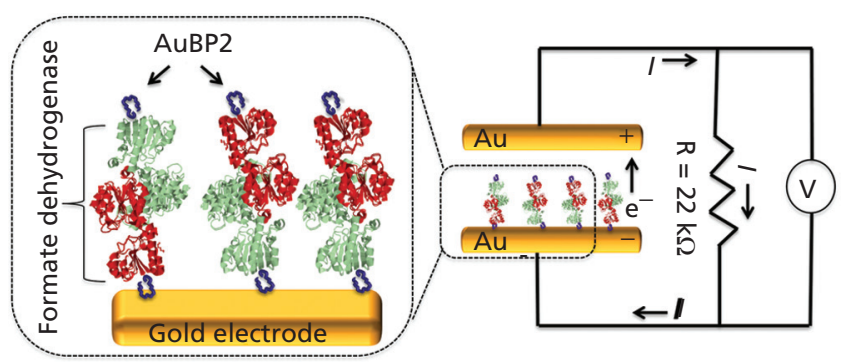

(a)

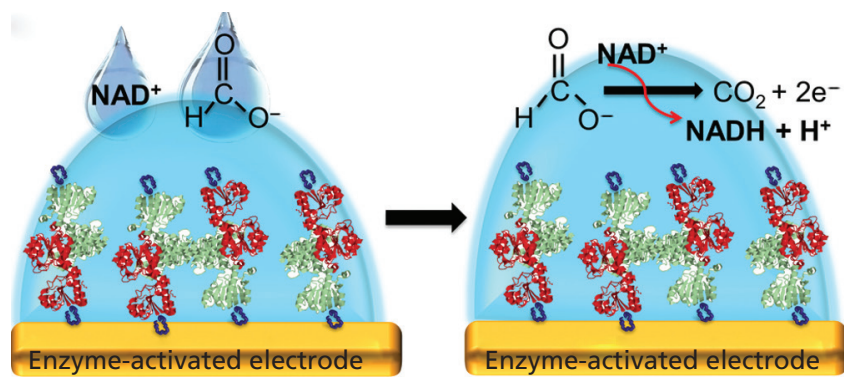

(b)

Figure 5. A schematic representation of (a) circuit-based biosensor and enzyme-activated gold electrode and (b) the catalytic conversion of formate by engineered enzyme immobilised onto the electrode surface. When the formate is oxidised, two electrons are transferred from the enzyme to the gold electrode in the solution. The structure shown is that of $\mathrm{NAD}^{+}$-dependent FDH from Candida boidinii (PDB ID: $2 J 6 I)^{56}$ of extending the duration of output voltage as well as current by subsequent additions of formate over multiple cycles. The circuit design can be further improved by optimising the physical layout and electrical connections as well as individual components, such as enzyme load, formate, internal and external resistances introduced to the system. Potentially, a bio-enabled circuit-based sensor system can be used for formate detection or NADH regeneration from $\mathrm{NAD}^{+}$by the pharmaceutical and agrochemical industries.

\section{Conclusions}

Herein, the authors describe genetically engineering a dehydrogenase to form a self-organised enzyme-integrated circuitbased sensor. Their approach is based on three steps: ( $a$ ) designing an engineered protein, which features an FDH catalytic unit from C. methylica and a highly specific gold-binding peptide (AuBP2) as a genetically conjugated tag that enables direct assembly of the enzyme onto a gold surface, $(b)$ corroborating the chimeric activities in the system by applying biochemical as well as surfacebinding assays and $(c)$ designing a circuit-based sensor system, which is integrated with the self-organised engineered enzyme, where the catalytic conversion of the formate can be monitored by the subsequent generation of electrons as an output in the current.

The developed design incorporates different novelties that are built by bridging genetic engineering to solid material interfaces to develop controlled interfacial interactions. While a structurally flexible spacer sequence is integrated as an engineering design parameter to keep the protein's distinct functionalities not to be

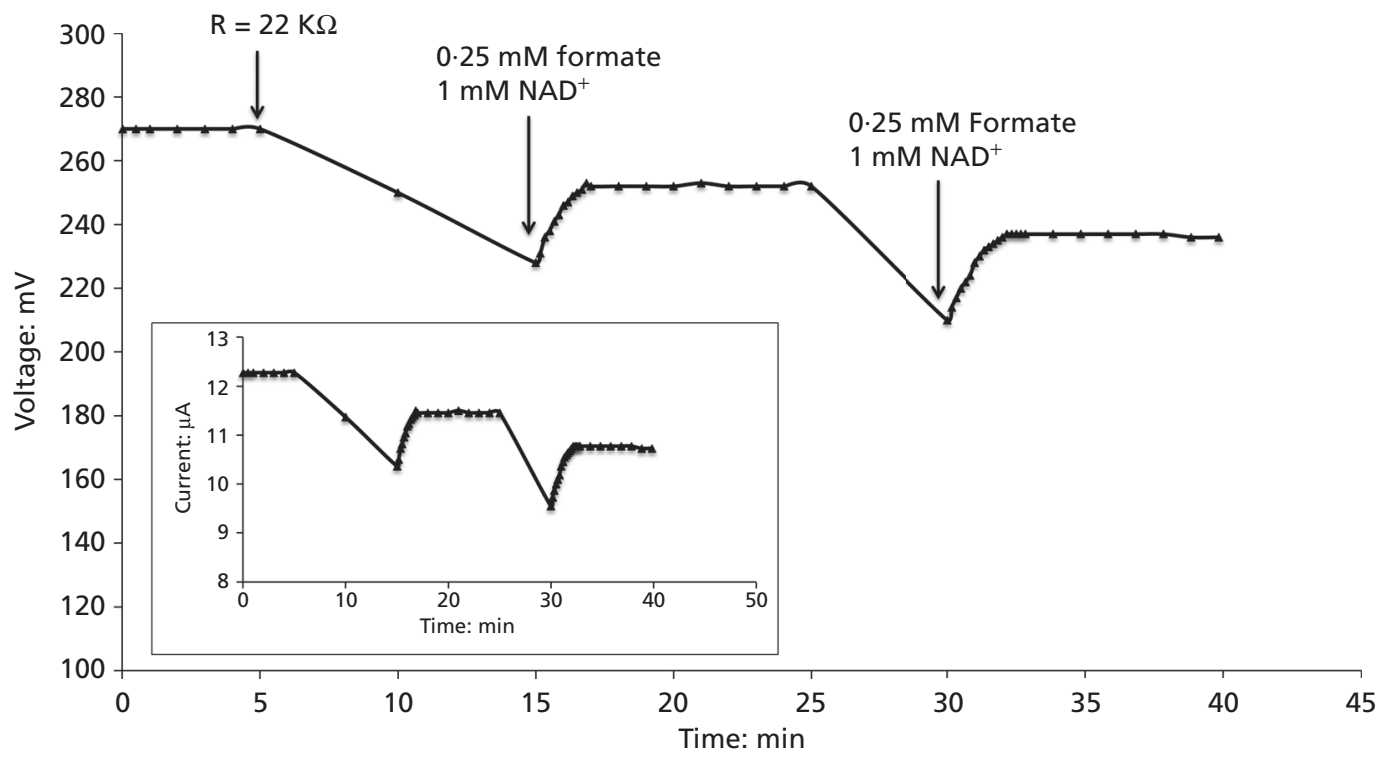

Figure 6. Change in output voltage (inset: change in current) in response to time built on self-immobilised enzyme-integrated electrode system. The attachment of the resistor to the electrodes is shown by the first arrow. The subsequent arrows refer to the sequential addition of substrate, that is, $0.25 \mathrm{mM}$ formate, into the solution 
Bioinspired, Biomimetic and Nanobiomaterials Volume 4 Issue BBN1
Direct bioelectrocatalysis at the interfaces by genetically engineered dehydrogenase Yucesoy et al. restricted by one another, the introduction of a new cleavage site allows for the removal of the purification tag to investigate the peptide as the sole effect on surface functionalisation. A singlestep assembly of the enzyme within a close proximity enabled to design a circuit-based electrode system where the authors verified the redox catalysis ability of the self-immobilised enzyme on the gold electrode by subsequent additions of formate. The proposed engineered fusion enzyme-based platform can be used for monitoring in a wide range of industrial applications, for example, formate detection in agrochemical industries or NADH regeneration from $\mathrm{NAD}^{+}$in pharmaceutical research and development sectors. The functional proteins genetically coupled with material-specific peptide tags offer a simple, single-step, biofriendly alternative to the conventional chemical and physical immobilisation methods, without the requirement of undesired surface activation processes. The proposed immobilisation strategy is a step towards achieving self-integrated enzyme-harbouring platforms and may lead to the improvement of sensing and fuel-cell devices in the future.

\section{Acknowledgements}

Dr Candan Tamerler would like to express her deep appreciation and sincere gratitude to Dr Kajal Mallick for his constant efforts to raise awareness in the bio-inspired, biomimetic and nano-biotechnology field. The authors will always remember him with his excitement, politeness and courteousness. Also, the authors greatly appreciate the University of Kansas Start Up and NFRFG Funds, TUBITAK2214-International Doctoral Research Fellowship for Banu Taktak Karaca. The authors also thank Dr Esra Yuca and Ryan S. Maloney's help in protein expression and purification.

\section{REFERENCES}

1. Tamerler, C.; Sarikaya, M. Molecular biomimetics: genetic synthesis, assembly, and formation of materials using peptides. MRS Bulletin 2008, 33, 504-512.

2. Sarikaya, M.; Tamerler, C.; Jen, A. K.-Y.; Schulten, K.; Baneyx, F. Molecular biomimetics: nanotechnology through biology. Nature Materials 2003, 2, 577-585.

3. Baneyx, F.; Park, J. K. Editorial: nanobio versus bionano what's in a name? Biotechnology Journal 2013, 8, 158-159.

4. Slocik, J. M.; Naik, R. R. Probing peptide-nanomaterial interactions. Chemical Society Reviews 2010, 39, 3454-3463.

5. Allred, D. B.; Cheng, A.; Sarikaya, M.; Baneyx, F.; Schwartz, D. T. Three-dimensional architecture of inorganic nanoarrays electrodeposited through a surface-layer protein mask. Nano Letters 2008, 8, 1434-1438.

6. Tang, Z.; Palafox-Hernandez, J. P.; Law, W.-C., et al. Biomolecular recognition principles for bionanocombinatorics: an integrated approach to elucidate enthalpic and entropic factors. ACS Nano 2013, 7, 9632-9646.
7. Tamerler, C.; Khatayevich, D.; Gungormus, M., et al. Molecular biomimetics: GEPI-based biological routes to technology. Peptide Science 2010, 94, 78-94.

8. Patolsky, F.; Timko, B. P.; Zheng, G.; Lieber, C. M. Nanowirebased nanoelectronic devices in the life sciences. MRS Bulletin 2007, 32, 142-149.

9. Elnathan, R.; Kwiat, M.; Pevzner, A., et al. Biorecognition layer engineering: overcoming screening limitations of nanowire-based FET devices. Nano Letters 2012, 12, 5245-5254.

10. Sassolas, A.; Blum, L. J.; Leca-Bouvier, B. D. Immobilization strategies to develop enzymatic biosensors. Biotechnology Advances 2012, 30, 489-511.

11. Katz, E.; MacVittie, K. Implanted biofuel cells operating in vivo - methods, applications and perspectives - feature article. Energy \& Environmental Science 2013, 6, 2791-2803.

12. Katz, E.; Minko, S.; Halámek, J.; MacVittie, K.; Yancey, $\mathrm{K}$. Electrode interfaces switchable by physical and chemical signals for biosensing, biofuel, and biocomputing applications. Analytical and Bioanalytical Chemistry 2013, 405, 3659-3672.

13. Asanomi, Y.; Yamaguchi, H.; Miyazaki, M.; Maeda, H. Enzyme-immobilized microfluidic process reactors. Molecules 2011, 16, 6041-6059.

14. Cetinel, S.; Dincer, S.; Cebeci, A., et al. Peptides to bridge biological-platinum materials interface. Bioinspired, Biomimetic and Nanobiomaterials 2012, 1, 143-153.

15. Hnilova, M.; Karaca, B. T.; Park, J., et al. Fabrication of hierarchical hybrid structures using bio-enabled layer-bylayer self-assembly. Biotechnology and Bioengineering 2012, 109, 1120-1130.

16. Fuentes, M.; Pessela, B. C.; Maquiese, J. V., et al. Reversible and strong immobilization of proteins by ionic exchange on supports coated with sulfate-dextran. Biotechnology Progress 2004, 20, 1134-1139.

17. Piletsky, S.; Piletska, E.; Bossi, A.; Turner, N.; Turner, A. Surface functionalization of porous polypropylene membranes with polyaniline for protein immobilization. Biotechnology and Bioengineering 2003, 82, 86-92.

18. Yam, C. M.; Deluge, M.; Tang, D.; Kumar, A.; Cai, C. Preparation, characterization, resistance to protein adsorption, and specific avidin-biotin binding of poly (amidoamine) dendrimers functionalized with oligo (ethylene glycol) on gold. Journal of Colloid and Interface Science 2006, 296, $118-130$.

19. Viitala, T.; Vikholm, I.; Peltonen, J. Protein immobilization to a partially cross-linked organic monolayer. Langmuir $\mathbf{2 0 0 0}$, 16, 4953-4961.

20. Mendes, R.; Carvalhal, R.; Kubota, L. Effects of different selfassembled monolayers on enzyme immobilization procedures in peroxidase-based biosensor development. Journal of Electroanalytical Chemistry 2008, 612, 164-172. 
Bioinspired, Biomimetic and Nanobiomaterials Volume 4 Issue BBN1
Direct bioelectrocatalysis at the interfaces by genetically engineered dehydrogenase Yucesoy et al.
21. Masri, M. S.; Friedman, M. Protein reactions with methyl and ethyl vinyl sulfones. Journal of Protein Chemistry 1988, 7 , 49-54.

22. Rusmini, F.; Zhong, Z.; Feijen, J. Protein immobilization strategies for protein biochips. Biomacromolecules 2007, 8, $1775-1789$.

23. Jongsma, M. A.; Litjens, R. H. Self-assembling protein arrays on DNA chips by auto-labeling fusion proteins with a single DNA address. Proteomics 2006, 6, 2650-2655.

24. Gauvreau, V.; Chevallier, P.; Vallières, K., et al. Engineering surfaces for bioconjugation: developing strategies and quantifying the extent of the reactions. Bioconjugate Chemistry 2004, 15, 1146-1156.

25. Lee, K.-B.; Park, S.-J.; Mirkin, C. A.; Smith, J. C.; Mrksich, M. Protein nanoarrays generated by dip-pen nanolithography. Science 2002, 295, 1702-1705.

26. Marcus, R. A.; Sutin, N. Electron transfers in chemistry and biology. Biochimica et Biophysica Acta (BBA) - Reviews on Bioenergetics 1985, 811, 265-322.

27. Kuila, T.; Bose, S.; Khanra, P., et al. Recent advances in graphene-based biosensors. Biosensors and Bioelectronics 2011, 26, 4637-4648.

28. Shao, Y.; Wang, J.; Wu, H., et al. Graphene based electrochemical sensors and biosensors: a review. Electroanalysis 2010, 22, 1027-1036.

29. Krauland, E. M.; Peelle, B. R.; Wittrup, K. D.; Belcher, A. M. Peptide tags for enhanced cellular and protein adhesion to single-crystalline sapphire. Biotechnology and Bioengineering 2007, 97, 1009-1020.

30. Whaley, S. R.; English, D.; Hu, E. L.; Barbara, P. F.; Belcher, A. M. Selection of peptides with semiconductor binding specificity for directed nanocrystal assembly. Nature $\mathbf{2 0 0 0}$, 405, 665-668.

31. Naik, R. R.; Stringer, S. J.; Agarwal, G.; Jones, S. E.; Stone, M. O. Biomimetic synthesis and patterning of silver nanoparticles. Nature Materials 2002, 1, 169-172.

32. Kacar, T.; Zin, M. T.; So, C., et al. Directed selfimmobilization of alkaline phosphatase on micro-patterned substrates via genetically fused metal-binding peptide. Biotechnology and Bioengineering 2009, 103, 696-705.

33. Khatayevich, D.; Gungormus, M.; Yazici, H., et al. Biofunctionalization of materials for implants using engineered peptides. Acta Biomaterialia 2010, 6, 4634-4641.

34. Puddu, V.; Perry, C. C. Peptide adsorption on silica nanoparticles: evidence of hydrophobic interactions. ACS Nano 2012, 6, 6356-6363.

35. Notman, R.; Walsh, T. R. Molecular dynamics studies of the interactions of water and amino acid analogues with quartz surfaces. Langmuir 2009, 25, 1638-1644.

36. Dai, H.; Choe, W.-S.; Thai, C. K., et al. Nonequilibrium synthesis and assembly of hybrid inorganic-protein nanostructures using an engineered DNA binding protein.
Journal of American Chemical Society 2005, 127, 15637-15643.

37. Sengupta, A.; Thai, C. K.; Sastry, M., et al. A genetic approach for controlling the binding and orientation of proteins on nanoparticles. Langmuir 2008, 24, 2000-2008.

38. Cetinel, S.; Caliskan, H. B.; Yucesoy, D. T., et al. Addressable self-immobilization of lactate dehydrogenase across multiple length scales. Biotechnology Journal 2013, 8, 262-272.

39. Hnilova, M.; Liu, X.; Yuca, E., et al. Multifunctional proteinenabled patterning on arrayed ferroelectric materials. ACS Applied Materials \& Interfaces 2012, 4, 1865-1871.

40. Yuca, E.; Karatas, A. Y.; Seker, U. O. S., et al. In vitro labeling of hydroxyapatite minerals by an engineered protein. Biotechnology and Bioengineering 2011, 108, 1021-1030.

41. Liu, W.; Wang, P. Cofactor regeneration for sustainable enzymatic biosynthesis. Biotechnology Advances 2007, 25, 369-384.

42. Hummel, W. Large-scale applications of $\mathrm{NAD}(\mathrm{P})$ dependent oxidoreductases: recent developments. Trends in Biotechnology 1999, 17, 487-492.

43. Tishkov, V. I.; Popov, V. O. Protein engineering of formate dehydrogenase. Biomolecular Engineering 2006, 23, 89-110.

44. Kratzer, R.; Pukl, M.; Egger, S.; Nidetzky, B. Whole-cell bioreduction of aromatic alpha-keto esters using Candida tenuis xylose reductase and Candida boidinii formate dehydrogenase co-expressed in Escherichia coli. Microbial Cell Factories 2008, 7, 37-48.

45. Karagüler, N. G.; Sessions, R. B.; Binay, B.; Ordu, E. B.; Clarke, A. R. Protein engineering applications of industrially exploitable enzymes: Geobacillus stearothermophilus LDH and Candida methylica FDH. Biochemical Society Transactions 2007, 35, 1610-1615.

46. Reda, T.; Plugge, C. M.; Abram, N. J.; Hirst, J. Reversible interconversion of carbon dioxide and formate by an electroactive enzyme. Proceedings of National Academy of Sciences 2008, 105, 10654-10658.

47. Roche, J.; Groenen-Serrano, K.; Reynes, O.; Chauvet, F.; Tzedakis, T. NADH regenerated using immobilized FDH in a continuously supplied reactor - application to 1-lactate synthesis. Chemical Engineering Journal 2014, 239 , 216-225.

48. Bolivar, J. M.; Wilson, L.; Ferrarotti, S. A., et al. Evaluation of different immobilization strategies to prepare an industrial biocatalyst of formate dehydrogenase from Candida boidinii. Enzyme and Microbial Technology 2007, 40, 540-546.

49. Addo, P. K.; Arechederra, R. L.; Minteer, S. D. Evaluating enzyme cascades for methanol/air biofuel cells based on $\mathrm{NAD}^{+}$-dependent enzymes. Electroanalysis 2010, 22, 807-812.

50. Allen, S.; Holbrook, J. Isolation, sequence and overexpression of the gene encoding NAD-dependent formate dehydrogenase from the methylotrophic yeast Candida methylica. Gene 1995, 162, 99-104. 
Bioinspired, Biomimetic and Nanobiomaterials Volume 4 Issue BBN1
Direct bioelectrocatalysis at the interfaces by genetically engineered dehydrogenase Yucesoy et al.
51. Ordu, E. B.; Karagüler, N. G. Improving the purification of $\mathrm{NAD}^{+}$-dependent formate dehydrogenase from Candida methylica. Preparative Biochemistry and Biotechnology 2007, 37, 333-341.

52. Tamerler, C.; Oren, E. E.; Duman, M.; Venkatasubramanian, E.; Sarikaya, M. Adsorption kinetics of an engineered gold binding peptide by surface plasmon resonance spectroscopy and a quartz crystal microbalance. Langmuir 2006, 22, 7712-7718.

53. Hnilova, M.; Oren, E. E.; Seker, U. O., et al. Effect of molecular conformations on the adsorption behavior of goldbinding peptides. Langmuir 2008, 24, 12440-12445.
54. Buck, R. P.; Lindner, E. Recommendations for nomenclature of ionselective electrodes (IUPAC Recommendations 1994). Pure and Applied Chemistry 1994, 66, 2527-2536.

55. Enemchukwu, M.; Tafesse, F. Phosphate sensitive electrodes in model studies for phosphorylation and dephosphorylation reactions. Analytical Letters 2013, 46, 663-670.

56. Schirwitz, K.; Schmidt, A.; Lamzin, V. S. High-resolution structures of formate dehydrogenase from Candida boidinii. Protein Science 2007, 16, 1146-1156.

\section{WHAT DO YOU THINK?}

To discuss this paper, please email up to 500 words to the managing editor at bbn@icepublishing.com

Your contribution will be forwarded to the author(s) for a reply and, if considered appropriate by the editor-inchief, will be published as a discussion in a future issue of the journal.

ICE Science journals rely entirely on contributions sent in by professionals, academics and students coming from the field of materials science and engineering. Articles should be within 5000-7000 words long (short communications and opinion articles should be within 2000 words long), with adequate illustrations and references. To access our author guidelines and how to submit your paper, please refer to the journal website at www.icevirtuallibrary.com/bbn 